\title{
The development of tension pneumothorax during mask ventilation under general anesthetic induction
}

\author{
Kee-Hoon Jang, Mi-Young Kwon, Min Seok Koo, Gunn-Hee Kim, and Jieun Kim \\ Department of Anesthesiology and Pain Medicine, National Medical Center, Seoul, Korea
}

Elevated peak inspiratory pressure (PIP) can cause pulmonary barotrauma during general anesthetic induction [1]. However, in patients who have bulla, tension pneumothorax can occur even if PIP is not highly elevated. We report a case of tension pneumothorax which occurred during anesthetic induction. The patient was a 67-year-old male scheduled for video-assisted thoracoscopic (VATS) bullectomy. He weighed $45 \mathrm{~kg}$ and was 163 $\mathrm{cm}$ tall. He was diagnosed with the human immunodeficiency virus (HIV) prior to pneumocystis pneumonia. His medical history included atrial fibrillation and chronic obstructive pulmonary disease (COPD). Physical examination revealed crackles and coarse lung sounds in both fields.

Preoperative arterial blood gas analysis in room air showed a hydrogen ion concentration $(\mathrm{pH})$ of 7.50 , a partial pressure of arterial carbon dioxide $\left(\mathrm{PaCO}_{2}\right)$ of $26 \mathrm{mmHg}$, a partial pressure of arterial oxygen $\left(\mathrm{PaO}_{2}\right)$ of $71 \mathrm{mmHg}$, and an arterial oxygen saturation $\left(\mathrm{SaO}_{2}\right)$ of $96 \%$. Radiologic findings showed a sizeable cyst which had recently developed in the right lower lobe (Fig. 1). Pulmonary function test presented severe obstructive pattern possibly combined with restriction: predicted percentage of Forced expiration value after 1 second (FEV1) was $28 \%$, predicted percentage of forced vital capacity (FVC) was 75\%, and FEV1/FVC ratio was $28 \%$.

$\mathrm{He}$ arrived at the operating room without premedication. The vital signs prior to anesthetic induction were as followes: a blood pressure of 110-115/55-60 mmHg, an atrial fibrillation rhythm with a heart rate about 90 beats/min, and a peripheral oxygen saturation $\left(\mathrm{SpO}_{2}\right)$ of $94 \%$ in room air. The left radial artery was cannulated with a 20 -gauge catheter for continuous monitoring of systemic blood pressure. After preoxygenation, we administered 2\% propofol with the Master target-controlled infusion (Orchestra ${ }^{\circledR}$ Base Primea; Fresenius-MCM GmbH, Germany) after administration of lidocaine (40 mg). After confirming loss of consciousness, we administered rocuronium $(0.5 \mathrm{mg} / \mathrm{kg})$, and remifentanil TCI was started. Assisted and controlled ventilation using mask and reservoir bag with $\mathrm{O}_{2} 6 \mathrm{~L} / \mathrm{min}$ was applied. Airway pressure release valve was set in $20 \mathrm{cmH}_{2} \mathrm{O}$ and PIP was maintained below $20 \mathrm{cmH}_{2} \mathrm{O}$ during ventilation.

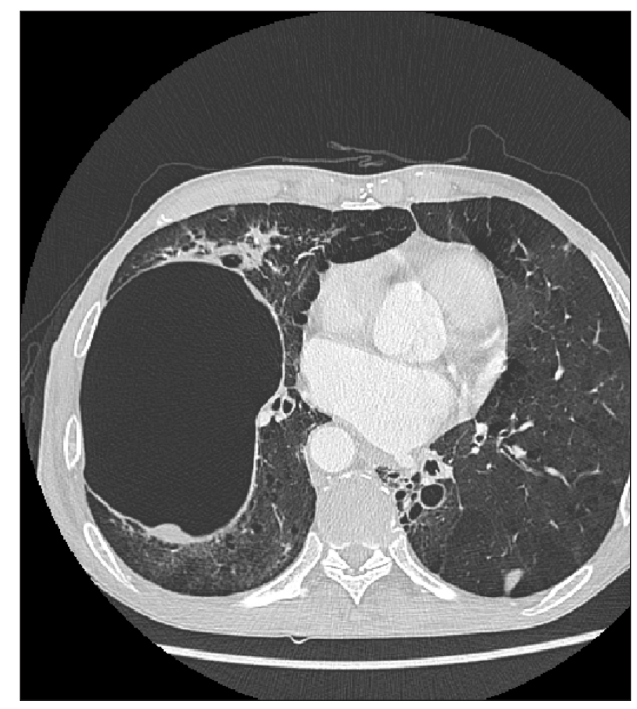

Fig. 1. Chest computed tomography showed an $8 \times 12 \mathrm{~cm}$ sized bulla in right lung.

Corresponding author: Mi-Young Kwon, M.D., Department of Anesthesiology and Pain Medicine, National Medical Center, 18-79, Euljiro 6-ga, Jung-gu, Seoul 100-799, Korea. Tel: 82-2-2260-7368, Fax: 82-2-2262-4766, E-mail: mykwon.nmc@gmail.com

(c) This is an open-access article distributed under the terms of the Creative Commons Attribution Non-Commercial License (http:// creativecommons.org/licenses/by-nc/3.0/), which permits unrestricted non-commercial use, distribution, and reproduction in any medium, provided the original work is properly cited. 
Two minutes after conducting manual ventilation, increased airway resistance was noted and vital signs changed to an arterial blood pressure of $61 / 36 \mathrm{mmHg}$, a heart rate of 140 beats/min, and $\mathrm{SpO}_{2}$ decreased of $90 \%$. Intravenous $100 \mu \mathrm{g}$ bolus of phenylephrine was repeatedly injected and fluid volume loading was started. Clinical examination revealed absent breathing sounds over the right hemithorax during mask ventilation and a hyperresonant note upon percussion. Arterial blood gas analysis revealed a $\mathrm{pH}$ of 7.19, $\mathrm{a} \mathrm{PaCO}_{2}$ of $60 \mathrm{mmHg}, \mathrm{a} \mathrm{PaO}_{2}$ of $30 \mathrm{mmHg}$, and $\mathrm{SaO}_{2}$ of $82 \%$. Assuming a bulla rupture in the right lung, single-time needle aspiration of pneumothorax was performed from the second intercostal space of midclavicular line, which was followed by improvement of the vital sign. Simultaneously endotracheal intubation was performed immediately with a 37-french left-sided endobronchial double-lumen tube (Broncho-cath ${ }^{\circledR}$; Mallinckrodt, Dublin, Ireland). After monitoring end-tidal carbon dioxide $\left(\mathrm{ETCO}_{2}\right)$ by capnogram, the decreased breathing sounds were verified in the right lung field. The initial $\mathrm{ETCO}_{2}$ value was $45 \mathrm{mmHg}$. Chest tube thoracotomy into the right thoracic cavity was performed by a thoracic surgeon. After chest tube insertion, vital signs showed an arterial blood pressure of $85-90 / 45-50 \mathrm{mmHg}$, an atrial fibrillation rhythm with heart rate of $105-115$ beats/min, and $\mathrm{SpO}_{2}$ of $99 \%$.

Central venous catheter was placed in the right jugular vein. Mechanical ventilation was performed with minute ventilation of $5 \mathrm{~L} / \mathrm{min}$. The $\mathrm{ETCO}_{2}$ was monitored by capnography and kept at $35-40 \mathrm{mmHg}$, and peak inspiratory pressure (PIP) showed 20 $\mathrm{cmH}_{2} \mathrm{O}$.

Thirty minutes after chest tube insertion, arterial blood gas analysis showed a $\mathrm{pH}$ of 7.17, a $\mathrm{PaCO}_{2}$ of $52 \mathrm{mmHg}, \mathrm{a} \mathrm{Pa}_{2}$ of $88 \mathrm{mmHg}$, and $\mathrm{SaO}_{2}$ of $97 \%$. VATS bullectomy was completed successfully, and patient's vital sign remained stable throughout the operation.

The present case is an example of tension pneumothorax followed by ruptured bulla during assisted and controlled ventilation with PIP $<20 \mathrm{cmH}_{2} \mathrm{O}$. Minutes after manual ventilation, airway resistance abruptly increased, desaturation developed and hemodynamics collapsed simultaneously. After we detected an absence of breathing sounds and a hyper-resonant note upon percussion at the right lung field, tension pneumothorax was strongly suspected.

Previous studies have shown that the prevalence of cysts upon radiologic examinations ranges from 10 to $34 \%$ in HIV patients with pneumocystis pneumonia [2]. Addtionally, many patients with COPD will develop cystic air spaces, known as a bulla, in the lung parenchyma. During anesthetic induction, it is difficult to diagnose tension pneumothorax because progressive hypoxia may be complicated by respiratory complications such as laryngospasm or bronchial spasm and low blood pressure may be compounded due to the cardiac depressive effects of the intravenous sedatives and inhalatives given during anesthetic induction. Positive-pressure ventilation should be applied cautiously in patients with bulla; airway pressures should be kept low and adequate expertise and equipment to relieve tension pneumothorax should be immediately available such as prompt chest tube insertion and lung isolation [3]. Upon the occurrence of tension pneumothorax, immediate and prompt treatments should follow. Physical examinations and chest radiography should be performed to exclude other causes of decreased oxygen saturation, but its prompt application can be delayed due to the associated hemodynamic instability. If radiologic examination is not possible, immediate decompression will be better if the patient shows low systolic blood pressure and declined $\mathrm{SpO}_{2}$ [4]. Blood pressure of the patient should be maintained using vasoconstrictors and inotropics. In the current case, chest radiography was not immediately available in the operating room and vital signs of the patient were unstable. Auscultation and percussion were performed quickly and the decision was made to perform immediate thoracic cavity decompression.

The present case highlights that pneumothorax should always be considered in the list of differential diagnoses when applying positive-pressure ventilation using mask and reservoir bag in patients with reduced compliance and large bullas. Anesthesiologist should pay careful attention to avoid airway pressure elevation and should meticulously monitor airway pressure. For HIV patients with pneumonia, careful assessment of a preexisting bulla should be done and adequate preparations should be made.

\section{References}

1. Oh SC, Son YS, Nam SW, Yoon KJ. Bronchospasm during the maintenance of general anesthesia. Korean J Anesthesiol 2005; 49 : 532-7.

2. Tung KT. Cystic pulmonary lesions in AIDS. Clin Radiol 1992; 45: 149-52.

3. Slinger PD, Campos JH. Anesthesia for Thoracic Surgery. In: Miller's Anesthesia. 7th ed. Edited by Miller RD, Eriksson LI, Fleisher LA, Wiener-Kronish JP, Young WL: Philadelphia, Churchill Livingstone. 2010, pp 1819-87.

4. Leigh-Smith S, Harris T. Tension pneumothorax-time for a re-think? Emerg Med J 2005; 22: 8-16. 